\title{
Percutaneous Liver Biopsy in the Diagnosis of Pediatric Liver Diseases
}

\author{
SALAHUDDIN MAHMUD ${ }^{1}$, SYED SHAFI AHMED ${ }^{2}$, JAHIDA GULSHAN ${ }^{3}$, DILRUBA BEGUM ${ }^{4}$, \\ FARHANA TASNEEM ${ }^{5}$, MASHUD PARVEZ ${ }^{6}$
}

\begin{abstract}
Background: Liver is prone to different diseases including congenital, infections, metabolic and malignancies. Liver biopsy is an aggressive but definitive way to diagnose liver diseases.

Objective: To diagnose different types of liver diseases and to determine the safety of percutaneous liver biopsy by disposable Tru-Cut needle.

Materials \& Methods: A descriptive study was done in the department of Pediatric Gastroenterology, Hepatology \& Nutrition, Dhaka Shishu (Children) Hospital, Dhaka, Bangladesh from January 2014 to January 2016. After getting history, physical examination and ultrasonogram, the biopsy was done with the help of Tru-Cut needle of different sizes under local anesthetics (2\% lidocaine) with 3 hours fasting. The biopsy specimens were immediately fixed in 10\% formal-saline and alcohol. The tissues were processed in automatic tissue processor under standard condition.

Results: Age of the children was 1 month to 12 years with mean age of 3.1 years (3.1 \pm 0.763$)$ with a range from 1 month to 12 years and male:female ratio was 1.1:1. The most common histological diagnosis was neonatal hepatitis (23.3\%) followed by biliary atresia (16.7\%). There were chronic hepatitis (10.0\%), glycogen storage disease (10.0\%), cirrhosis (6.7\%) and hepatoblastoma (6.7\%) in moderate frequency. Other cases of least frequency (3.3\%) were fatty change, lipid storage disease, intra-hepatic bile duct paucity, congenital hepatic fibrosis and Von Meyenburg complex. Neonatal hepatitis \& biliary atresia were common among $\leq 1$ year age group and glycogen storage disease, hepatoblastoma \& non-specific changes in 1-5 year age group. In the older children (>5 years), chronic hepatitis (10.0\%) \& cirrhosis (6.6\%) were the common causes. Consanguinity was present in storage disease, neonatal hepatitis, congenital hepatic fibrosis, von meyenburg complex and intra-hepatic bile duct paucity. After biopsy, mild pain and discomfort was present in $23(38.3 \%)$ children, while diffuse pain which required analgesics in 11 (18.3\%) children without any major complications.
\end{abstract}

Conclusion: Liver biopsy is a useful and practical tool for the diagnosis of pediatric liver diseases. Neonatal hepatitis, biliary atresia, storage disorders and chronic hepatitis were common entities in our set up. Consanguinity was more common in hereditary and metabolic liver diseases. Liver biopsy is safe having minimal complications.

Key words: Liver biopsy (LB), Pediatric liver disease, Safety of biopsy

1. Assistant Professor, Pediatric Gastroenterology, Hepatology \& Nutrition, Bangladesh Institute of Child Health, Dhaka Shishu (Children) Hospital.

2. Professor \& Head, Pediatric Gastroenterology, Hepatology \& Nutrition, Bangladesh Institute of Child Health, Dhaka Shishu (Children) Hospital.

3. Associate Professor, Institute of Statistical Research and Training, University of Dhaka.

4. Associate Professor of Physiology, Dhaka Medical College, Dhaka.

5. Registrar, Neonatology, Apollo Hospitals, Dhaka.

6. Associate Professor of Histopathology, Dhaka Shishu (Children) Hospital.

Correspondence: Dr. Salahuddin Mahmud, Assistant Professor, Dhaka Shishu (Children) Hospital, Dhaka, Email: drsmbablu@gmail.com

\section{Introduction}

Hepatic disorders are one of the significant causes of morbidity and mortality in children ${ }^{1}$ The liver in pediatric age group suffers from different types of infections, metabolic and neoplastic disorders resulting in jaundice, deranged liver function tests and hepatomegaly. ${ }^{2}$ Treatment strategies are different for each disorder. So, it is obvious that a correct and prompt diagnosis has an important role in proper management of these children. ${ }^{3,4}$ Biliary atresia and neonatal hepatitis are the two common causes of 
cholestasis in neonatal period. ${ }^{2}$ They are very similar and the correct $\&$ definite diagnosis might be very difficult. Considering this fact that biliary atresia needs surgical intervention as soon as possible, in order to get a better outcome. ${ }^{1}$ Early diagnosis and prompt treatment offers the only chance for survival. Liver biopsy (LB) is the corner stone for exact diagnosis. ${ }^{5}$

Even in this era of advanced virological, immunological and molecular genetic testing, LB remains a useful diagnostic tool. ${ }^{6}$ It is the gold standard for diagnosis and is important in determining disease severity and prognosis. ${ }^{7}$ It is especially helpful in exploring the relationship between pathogenesis, pathomorphological features, clinical manifestations, and evaluation of therapeutic protocols. ${ }^{8}$ The role of LB in the management of patients with acute and chronic liver diseases has significantly evolved in recent years. ${ }^{9}$ It can change the clinical diagnosis in $8-14 \%$, the management in $12-18 \%$ and the frequency of liver test monitoring in $36 \%$ of cases. ${ }^{10}$ In the last $10-15$ years the number of liver biopsy have increased dramatically due to emerging liver transplantation and the identification of hepatitis $C$ virus. ${ }^{11}$

Paul Ehrlich in 1883, for the first time used needle biopsy to study the glycogen content of diabetic liver. In 1958, Menghini devised a $1.4 \mathrm{~mm}$ diameter needle for liver biopsy. Nowadays for histopathological evaluation a Tru-cut, Menghini, Vim-Silverman or Jamshidi needle are used. ${ }^{2}$ To prevent complications, several techniques (automatic needles, ultrasound guidance, conscious sedation, laparoscopic, transjugular LB) have been developed. Although traditionally performed 'blindly', there is growing evidence to suggest that US guidance in identifying the puncture site decreases the complications rate $^{12,13}$ and is cost-effective. ${ }^{14,15}$ The Patient Care Committee of the American Gastroenterological Association has stated that the liver biopsy "appears to be more accurate and perhaps more safe when performed in conjunction with ultrasound guidance". ${ }^{16}$ Most hepatologists agree that all patients should undergo ultrasonography of the liver before a percutaneous biopsy is performed. ${ }^{11}$

The needle biopsy represents $1 / 50,000$ parts of liver parenchyma. However the focal lesions can be missed with this technique. A satisfactory biopsy tissue is 1$4 \mathrm{~cm}$ long and $10-50 \mathrm{mg}$ in weight. ${ }^{17}$ The objective of this study was to diagnose the different pediatric liver diseases and also to look into the safety of biopsy.

\section{Materials and Methods}

A descriptive study was conducted in the department of Pediatric Gastroenterology, Hepatology \& Nutrition, Dhaka Shishu (Children) Hospital, Dhaka, Bangladesh from January 2014 to January 2016. A total of 69 admitted cases of neonatal cholestasis, chronic liver disease with or without cirrhosis, suspected hepatic neoplasm, suspected metabolic liver disease or storage disease, unexplained hepatomegaly, persistent abnormal liver function test or raised ALT/ SGPT and abnormal appearance of liver on a scan between 1 month to 12 years of age were enrolled in this study after obtaining their consent. However, patients with huge ascites, increased prothrombin time (INR >1.3), anemia ( $\mathrm{Hb}<10 \mathrm{gm} / \mathrm{dl})$, thrombocytopenia (platelet count $<80,000 / \mathrm{cu} \mathrm{mm}$ of blood) with prolong bleeding and/or clotting time were excluded from the study. Out of 69 cases, 60 were analyzed due to inadequate specimen ( $<2$ portal areas). An ultrasound of liver was routinely performed before the procedure to mark the site of percutaneous biopsy and to exclude any intra-hepatic cystic lesion. Ultrasonography guided LB was done in a case of hepatic neoplasms to locate the actual site of hepatic mass.

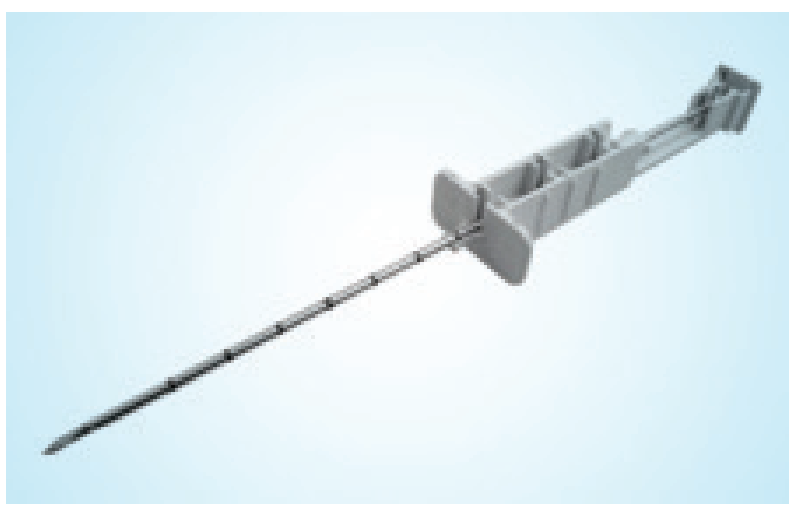

Fig.-1: Tru-cut liver biopsy needle

The biopsy was done with the help of Tru-Cut needle of different sizes under local anesthetics $(2 \%$ lidocaine) with 3 hours fasting (Fig-1). Biopsy needle of diameter $18 \mathrm{G} \times 7.6 \mathrm{~cm}$ for $<5$ years, $18 \mathrm{G} \times 11 \mathrm{~cm}$ for $5-10$ years and $18 \mathrm{G} \times 15 \mathrm{~cm}$ for $>10$ years of children were used. The biopsy specimens were immediately fixed in $10 \%$ formal-saline and carnoy's solution was used as a preservative for those suspected for glycogen storage disorders. The sample was clearly labeled with the patient's details, sample type, date and time, prior to sending it to the histopathology department. The specimen was transported 
immediately to the laboratory, so that it could be processed correctly. The tissues were processed and the paraffin embeded tissues were cut with the help of manual microtome. Four to six micron thick serial sections were then stained with routine Haematoxylin and Eosin (H\&E) stain and the special PAS stains, Masson Trichrome stain and others if required (Fig-2).

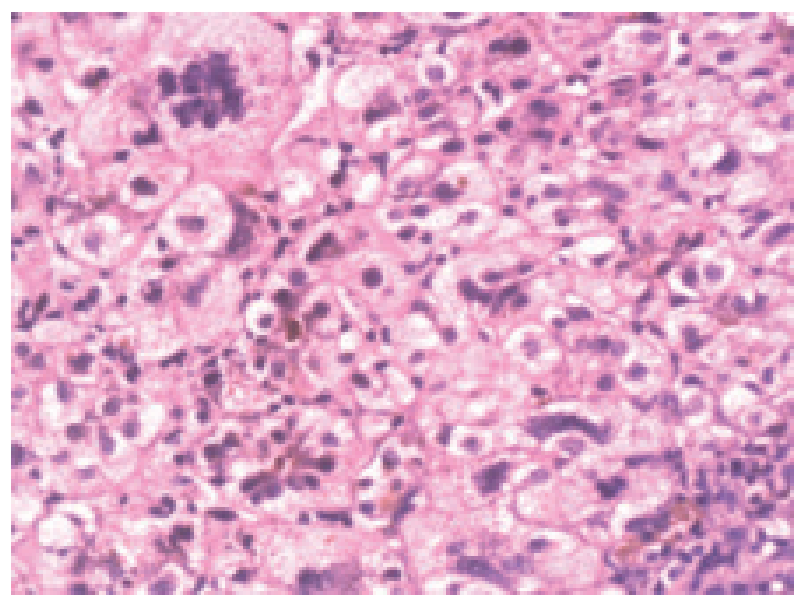

Fig.-2: Neonatal giant cell hepatitis. Many of the hepatocytes are markedly enlarged and show prominent multinucleation and cholestasis

After procedure, the child was suggested to lie on his bed with back for less chance of bleeding. The child was followed up for dressing soaked with blood, severe abdominal pain and/or excessive crying, recorded high grade temperature $\left(>38^{\circ} \mathrm{C}\right)$, respiratory distress, raised pulse rate with decrease $\mathrm{BP}$ and if needed complete blood count (CBC) done after 8 hours. An intravenous canula was kept in situ for 24 hours after biopsy for introduction of any emergency drugs or blood transfusion. Analgesics were given if present severe pain. Patients were allowed to eat and drink 2 hours post procedure if awake \& oriented. After 6 hours gentle walking only was recommended in older children.

A semi structured form was used as a data collection instrument. Data were analyzed by Statistical Package of Social Science (SPSS) version 20.0 programme. Descriptive analysis was performed for demographic, clinical and radiographic features, and results were presented as mean \pm standard deviation for quantitative variables and frequencies (percentages) for qualitative variables.

\section{Results}

Out of 60 children of liver diseases, 26 (43.3\%) were 1 year or less, $20(33.3 \%)$ between $1-5$ years, 10 $(16.7 \%)$ between $5-10$ years and $4(6.7 \%)$ more than 10 years of age (Fig-3) The minimum \& maximum ages were 1 month and 12 years respectively.

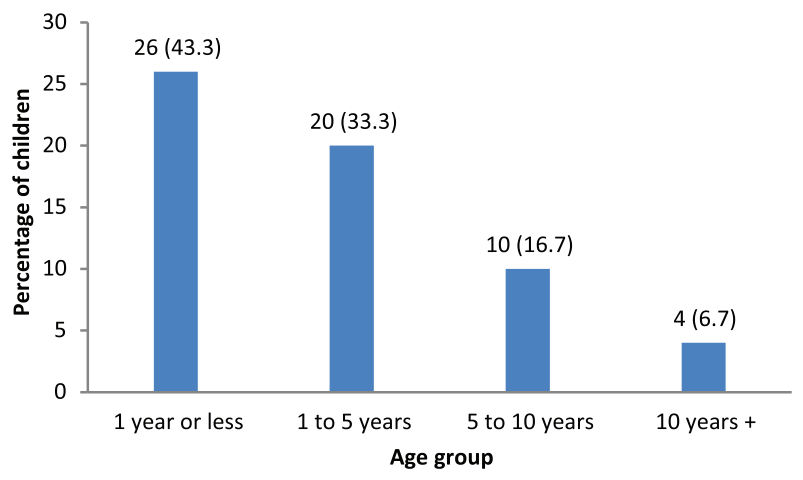

Fig.-3: Distribution of children by age $(n=60)$

The proportion of male children was little higher than female children with a male to female ratio of 1.1:1 (Fig-4)
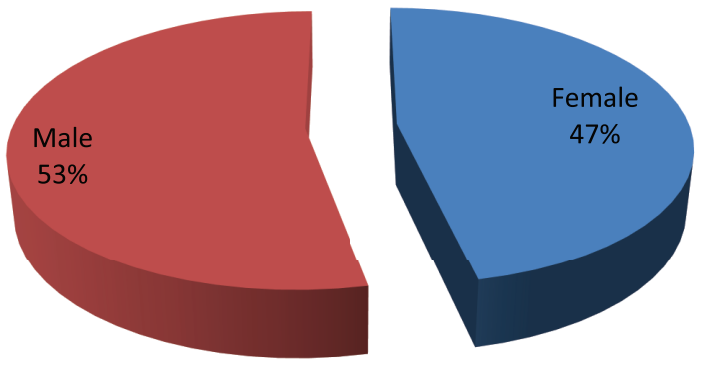

Fig-4: Distribution of children by sex $(n=60)$

Specific histological changes were found in $90 \%$ cases \& non-specific changes in $10 \%$ cases. The most common histological diagnosis was neonatal hepatitis (23.3\%) followed by biliary atresia (16.7\%). Other diseases were chronic hepatitis $(10.0 \%)$, glycogen storage disease $(10.0 \%)$, cirrhosis $(6.7 \%)$ and hepatoblastoma $(6.7 \%)$ in moderate frequency. Other less frequently (3.3\%) cases were fatty change, lipid storage disease, intra-hepatic bile duct paucity, congenital hepatic fibrosis and Von Meyenburg complex (Table-I). 
BANGLADESH J CHILD HEALTH 2016; VOL 40 (2) : 75 Percutaneous Liver Biopsy in the Diagnosis of Pediatric Liver Diseases

Table I

Distribution of children by type of disorders

\begin{tabular}{lcc}
\hline Type of Disorder & Frequency & Percent \\
\hline Neonatal hepatitis & 14 & 23.3 \\
Biliary Atresia & 10 & 16.7 \\
Chronic Hepatitis & 6 & 10.0 \\
Glycogen storage disease & 6 & 10.0 \\
Non-specific change & 6 & 10.0 \\
Cirrhosis & 4 & 6.7 \\
Hepatoblastoma & 4 & 6.7 \\
Fatty change & 2 & 3.3 \\
Lipid Storage disease & 2 & 3.3 \\
Intra-hepatic bile duct paucity & 2 & 3.3 \\
Congenital hepatic fibrosis & 2 & 3.3 \\
Von Meyenburg complex & 2 & 3.3 \\
\hline Total & 60 & 100.0 \\
\hline
\end{tabular}

In the studied children, highest number of liver diseases were present in $<1$ year $(43.3 \%)$ age group followed by $1-5$ year (33.3\%) group. Neonatal hepatitis \& biliary atresia were common among d" 1 year age group and glycogen storage disease, hepatoblastoma \& non-specific changes in 1-5 year age group. In the older children ( $>5$ years), chronic hepatitis $(10.0 \%) \&$ cirrhosis $(6.6 \%)$ were the common causes (Table-II).

Overall, consanguinity was present in $30 \%$ cases among all subjects (Fig.-5). It was present in storage disease, neonatal hepatitis, congenital hepatic fibrosis, Von Meyenburg complex and intra-hepatic bile duct paucity (Table-III).

Table-II

Age-wise distribution of childhood hepatic diseases $(n=60)$

\begin{tabular}{lccccc}
\hline Disorders of liver & 1 year or less & $1-5$ year & $5-10$ year & 10 year + & Total \\
\hline Neonatal hepatitis & 14 & - & - & - & 14 \\
Biliary atresia & 10 & - & - & - & 10 \\
Intra-hepatic bile duct paucity & 02 & - & - & - & 02 \\
Glycogen storage disease & - & 06 & - & - & 06 \\
Hepatoblastoma & - & 04 & - & - & 04 \\
Lipid storage disease & - & 02 & - & - & 02 \\
Congenital hepatic fibrosis & - & 02 & - & - & 02 \\
Non-specific change & - & 04 & 02 & - & 06 \\
Von Meyenburg complex & - & 02 & - & - & 02 \\
Chronic hepatitis & - & - & 06 & - & 06 \\
Fatty change & - & - & 02 & - & 02 \\
Cirrhosis & - & - & - & 04 & 04 \\
\hline Total & 26 & 20 & 10 & 04 & 60 \\
\hline
\end{tabular}

Table-III

Distribution of children by consanguinity $(n=60)$ :

\begin{tabular}{lccc}
\hline Diagnosis & Consanguinity Present & Consanguinity Absent & Total \\
\hline Glycogen storage disease & 06 & 00 & 06 \\
Lipid storage disease & 02 & 00 & 02 \\
Congenital hepatic fibrosis & 02 & 00 & 02 \\
Von Meyenburg complex & 02 & 00 & 02 \\
Intra-hepatic bile duct paucity & 01 & 01 & 02 \\
Neonatal hepatitis & 05 & 09 & 14 \\
Biliary atresia & 00 & 10 & 10 \\
Chronic hepatitis & 00 & 06 & 06 \\
Non-specific change & 00 & 06 & 06 \\
Cirrhosis & 00 & 04 & 04 \\
Hepatoblastoma & 00 & 04 & 04 \\
Fatty change & 00 & 02 & 02 \\
\hline Total & 18 & 42 & $60(30 \%)$ \\
\hline
\end{tabular}




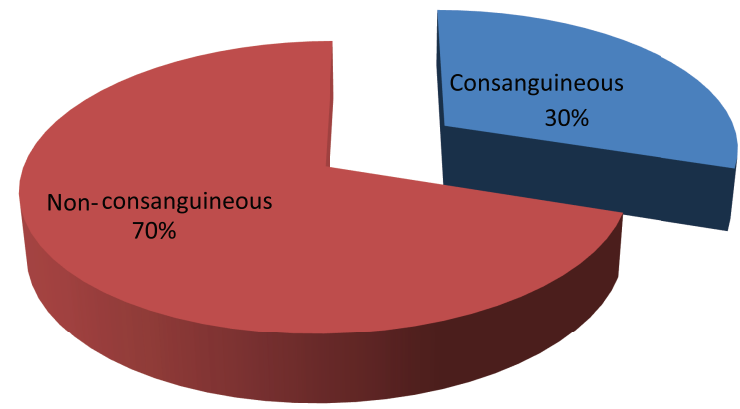

Fıg.-๖: LIstributıon or cnılaren py consanguınıty ( $n=0 \mathrm{oU})$

After biopsy, mild pain and discomfort was present in $23(38.3 \%)$ children, while diffuse pain which required analgesics in 11 (18.3\%) children. Major complications like perforation or peritonitis was absent in studied children.

Table-IV

Complications after liver biopsy $(n=60)$ :

\begin{tabular}{lcc}
\hline Complications & Frequency & Percent \\
\hline Mild pain \& Discomfort & 23 & 38.3 \\
Diffuse pain required analgesics & 11 & 18.3 \\
Bleeding & 00 & 00 \\
Peritonitis & 00 & 00 \\
Perforation & 00 & 00 \\
\hline Total & 34 & 56.6 \\
\hline
\end{tabular}

\section{Discussion}

The incidence of liver diseases in children has increased in the recent years. The initial clinical presentation and laboratory work up in many of these diseases may be similar and a definite diagnosis often made by specialized laboratory investigation and histologic examination of liver tissue. ${ }^{18}$ For patients who suffer from hepatomegaly and present with abnormal liver function tests or unexplained jaundice, a liver biopsy is the best and the only way to attain the correct diagnosis. ${ }^{2}$ Histopathological evaluation of the liver can provide unavailable information regarding its structure as well as the type and severity of damage or fibrosis that involve the liver. It is also helpful for monitoring the efficacy of treatment. Percutaneous liver biopsy in children is a procedure with a low rate of major complications and a high rate of minor bleeding as well as no need for intervention and is considered as a safe procedure even in infancy. ${ }^{19-24}$
In this study, mean age was 3.1 years $(3.1 \pm 0.763)$ with a range from 1 month to 12 years. Majority of the children were $<1$ year $(43.3 \%)$ of age. Roohi et al. ${ }^{6}$ found mean age 4.2 years with a range of 10 days to 14 years. The peak incidence was also observed in $<1$ year age group which was similar to present study. The mean age revealed that neonatal cholestasis appears in children at very early age. Present study showed male to female ratio of 1.1:1 which is near similar with the study of Ahmed et al. ${ }^{6}$ (1.2:1) and Sabir et al. ${ }^{25}(1.4: 1)$.

In the present study, the most common histological diagnosis was neonatal hepatitis $(23.3 \%)$ followed by biliary atresia $(16.7 \%)$ which is similar to study of Ahmed et al. ${ }^{6}$ (neonatal hepatitis $20 \%$ \& biliary atresia $20 \%$ ). But Sabir et al. ${ }^{25}$, Alam et al. ${ }^{11}$ and Roohi et al. ${ }^{6}$ showed different results. In each study cirrhosis ( $26 \%, 16.7 \%$ \& $15.7 \%$ respectively) was the dominant one. The possible underlying reason could be the age of the children which were different in different studies. In the present study, majority of children were less than 1 year of age (43.3\%) and in the other studies (For example, Alam et al. ${ }^{11}$ ), most of the children were $1-5$ years $(46.7 \%)$ and $>5$ years $(50.0 \%)$ age group. In our study, chronic hepatitis (10.0\%), glycogen storage disease $(10.0 \%)$, cirrhosis $(6.7 \%)$ and hepatoblastoma $(6.7 \%)$ were found in moderate frequency. But Deghani et al. ${ }^{1}$ found chronic hepatitis $(23.1 \%)$ in majority of children.

Neonatal hepatitis $(53.8 \%)$ \& biliary atresia $(38.4 \%)$ was common among d" 1 year age group. Sabir et al. ${ }^{25}$ (neonatal hepatitis $84 \%$ \& biliary atresia $42 \%$ ) also observed the similar result. Glycogen storage disease (30\%), hepatoblastoma (20\%) \& non-specific changes $(20 \%)$ were the most common in 1-5 year age group. Deghani et al. ${ }^{1}$ and Ahmed et al. ${ }^{6}$ also observed similar result. In the older children ( $>5$ years), chronic hepatitis $(10.0 \%) \&$ cirrhosis $(6.6 \%)$ were the two most common causes which is consistent with the result of Sabir et al. ${ }^{25}$ As age increases, chronic hepatitis and liver cirrhosis became the dominant diagnoses.

Roohi et al. ${ }^{6}$ reported history of consanguinity in 10 (18.5\%) among 54 cases which included 3 cases each of neonatal hepatitis \& cirrhosis, and one case each of Wilson's disease, hemosiderosis, glycogen storage disease \& non-cirrhotic portal fibrosis. In present study, consanguinity was present in $18(30 \%)$ cases out of 60 which were included neonatal hepatitis, glycogen 
storage disease, lipid storage disease and congenital hepatic fibrosis. In neonatal hepatitis, consanguinity may be present in $20 \%$ cases. As glycogen storage disease is a autosomal recessive disorder, so consanguinity is one of the contributory factors.

In the present study, non-specific change or nonspecific reactive hepatitis were found in $6(10 \%)$ out of 60 cases. Deghani et al. ${ }^{1}$ (16.2\%) also observed the near similar result. But Ahmed et al, ${ }^{2}$ observed only $3 \%$ such cases. The relatively-high percentage of non-diagnostic biopsies can be due to lack of more specific tests and enzyme studies on the liver tissue and also absence of electron microscopic examination of liver tissues in our center.

Liver biopsy is a safe procedure when performed by a experienced operator. ${ }^{6}$ Pain after LB is mild, well tolerated and controlled by minor analgesia. ${ }^{9}$ In the present study, only mild pain \& discomfort were found in $38.3 \%$ cases where diffuse pain that required analgesics were found only $18.3 \%$ cases which is quite similar as shown by Alam et al. ${ }^{11}$ (36.7\% and $10 \%$ respectively). There are two factors demonstrated to be associated with an intense pain requiring analgesics: cutting biopsy needles and less experienced operators. ${ }^{9}$ Although Ahmed et al. ${ }^{2}$ observed that bleeding $(6.7 \%)$ \& peritonitis $(3.3 \%)$ were present after LB and Dezsofi et al. ${ }^{9}$ reported bleeding in $2.8 \%$ cases and bile leakage in $0.6 \%$ cases after the procedure, there was no major complications observed in present study.

\section{Limitations of study}

The main limitation of the present study is that was a single-centre study with a limited sample size.

\section{Conclusions}

Percutaneous liver biopsy is a simple, useful, costeffective and accurate diagnostic technique for the diagnosis of pediatric liver diseases. Neonatal hepatitis, biliary atresia, storage diseases and chronic hepatitis were the common histological diagnoses. Neonatal hepatitis \& biliary atresia were common in infancy and chronic hepatitis \& cirrhosis were frequent in older children. Consanguinity was more common in hereditary and metabolic liver diseases. Liver biopsy is safe with minimal complications.

\section{References}

1. Dehghani SM, Haghighat $M$, Imanieh $M H$, Geramizadeh B, Eskandari Z, Erfanifar F et al. Percutaneous Needle Biopsy in the diagnosis of liver diseases in children. J Compr Ped. 2013; 4(4): $184-88$

2. Ahmed M, Afzal S, Roshan E, Mubarik A, Bano $S$, Khan SA et al. Usefulness of needle biopsy in the diagnosis of pediatric liver disorders. J Pak Med Assoc. 2005;55:24-28.

3. Lai MW, Chang MH, Hsu SC, Hsu HC, Su CT, Kao CL, et al. Differential diagnosis of extrahepatic biliary atresia from neonatal hepatitis: a prospective study. J Pediatr Gastroenterol Nutr.1994; 18(2): 121-7.

4. Dehghani SM, Haghighat M, Imanieh MH, Geramizadeh B. Comparison of different diagnostic methods in infants with Cholestasis. World J Gastroenterol. 2006; 12(36):5893-6.

5. Bazeria JA, Balistreri WF. Cholestatic syndromes of infancy and childhood. Semin Gastrointest. 2001; 12: 54-65.

6. Roohi S, Ingin RJ, Wadankeri SS, Pattankar VL, Andola SK. Clinicopathological study of liver biopsies in pediatric patients. Asin J Med Cli Sci. 2013; 2(1): 17-20

7. Campbel MS, Reddy KR. Review article: The evolving role of liver biopsy. Aliment Pharmacol Ther. 2004; 20: 249-59.

8. Zhang HF, Yang XJ, Zhu SS, Zhao JM, Zhang $\mathrm{TH}, \mathrm{Xu} Z \mathrm{Z}$, et al. Pathological changes and clinical manifestations of 1020 children with liver diseases confirmed by biopsy. Hepatobilliary Pancreat Dis Int. 2004; 3: 395-8.

9. Dezsofi A, Baumann U, Dhawan A, Durmaz O, Fischler $\mathrm{B}$, Hadzic $\mathrm{N}$ et al. Liver biopsy in children: Position paper of the ESPGHAN hepatology committee. JPGN. 2015; 60(3): 408-20.

10. Sheela H, Seela S, Caldwell C, Boyer JL, Jain D. Liver Biopsy: evolving role in the new millennium. J Clin Gastroenterol. 2005; 39: 603-10.

11. Alam J, Mobarak R, Arefin S, Sarker NR, Tayab A, Tahera A et al. Liver biopsy in children in Dhaka Shishu Hospital: A study of 30 cases. Bangladesh J Child Health. 2010; 34(1): 1-6.

12. Reddy KR, Schiff ER. Complications of liver biopsy. In: Taylor MB, editor. Gastrointestinal emergencies. 2nd ed. Baltimore: Williams \& Wilkins, 1997; pp. 959-68. 
13. Lindor KD, Bru C, Jorgensen RA, Rakela J, Bordas JM, Gross JB, et al. The role of ultrasonography and automatic-needle biopsy in outpatient percutaneous liver biopsy. Hepatology. 1996; 23: 1079-83.

14. Caturelli E, Giacobbe A, Facciorusso D, Bisceglia M, Villani MR, Siena DA, et al. Percutaneous biopsy in diffuse liver disease: increasing diagnostic yield and decreasing complication rate by routine ultrasound assessment of puncture site. Am J Gastroenterol. 1996; 91: 1318-21.

15. Pasha T, Gabriel S, Therneau T, Dickson ER, Lindor KD. Cost-effectiveness of ultrasoundguided liver biopsy. Hepatology.1998; 27: 1220-26.

16. Cadranel JF, Rufat $P$, Degos F. Practices of liver biopsy in France: results of a prospective nationwide survey. For the Group of Epidemiology of the French Association for the Study of the Liver (AFEF). Hepatology. 2000; 32: 477-81.

17. Sherlock $S$. Needle biopsy of the liver. Diseases of liver and biliary system. 5th ed. Oxford: Blackwell, 1995; pp. 44-54.

18. Zhang HF, Yang XJ, Chen JM, Wang LJ, Zhu SS, Xu ZQ, et al. Clinical application of liver biopsy in children: a report of 511 cases. Chin J Pediatr. 1998; 36: 31-33
19. Holtz T, Moseley RH, Scheiman JM. Liver biopsy in fever of unknown origin. A reappraisal. J Clin Gastroenterol. 1993; 17(1): 29-32.

20. Ozawa K, Mori K, Morimoto T. Evaluation of hepatic function. Curr Opin Gen Surg. 1994; 3 : 17-23.

21. Westheim BH, Ostensen AB, Aagenaes I, Sanengen T, Almaas R. Evaluation of risk factors for bleeding after liver biopsy in children. J Pediatr Gastroenterol Nutr. 2012; 55(1): 82-7.

22. El-Shabrawi MH, El-Karaksy HM, Okahsa SH, Kamal NM, El-Batran G, Badr KA. Outpatient blind percutaneous liver biopsy in infants and children: is it safe? Saudi J Gastroenterol. 2012; 18(1): 26-33.

23. Matos H, Noruegas MJ, Goncalves I, Sanches C. Effectiveness and safety of ultrasound-guided percutaneous liver biopsy in children. Pediatr Radiol 2012; 42(11): 1322-5.

24. Potter C, Hogan MJ, Henry-Kendjorsky K, Balint J, Barnard JA. Safety of pediatric percutaneous liver biopsy performed by interventional radiologists. J Pediatr Gastroenterol Nutr. 2011; 53(2): 202-6.

25. Sabir OM. Pathologic causes of liver disease in Sudanese children: Results of 450 liver needle biopsies at a single children hospital. Sudan J Pediatr 2011; 11(1): 38-41. 